\title{
FAMA AND FRENCH THREE FACTOR MODEL APPLICATION IN THE PAKISTAN STOCK EXCHANGE (PSE)
}

\author{
Athar Iqbal \\ Assistant Professor, Iqra University \\ Akhtiar AliPeter \\ Xavier D'Abreo
}

\begin{abstract}
Purpose: This research has been carried out to test empirically the application of Fama and French three factor model on Pakistan Stock Exchange covering forty listed companies using annual data from 1984 to 2012.

Methodology: Author selected excess return as dependent variable and three independent variables market risk, size of the firm and the book to market value of the firms in the portfolio. To test the hypotheses, author used panel least square method.

Findings: Result shows that all independent variables are significant and have sign as predicted by theoretical understanding. From our result we interpret that three factors model explain returns in its simplified form on long term horizon better than single factor model like CAPM.

Implication: The findings of the research paper suggest that developing economy like Pakistan investor and portfolio manager can better understand by applying multiple variable models and its modified form rather than only relying on CAMP covariance sensitivity model.
\end{abstract}

Key Words: Modern portfolio theory, excess return, risk and return, three factors Jel Classification: G3, G11,G12, G20

*The material presented by the author does not necessarily portray the view point of the editors and the management of the Institute of Business \& Technology - IBT

1. Athar Iqbal

: athar@iqra.edu.pk

2. Akhtiar Ali

: akhtiar.ali@hotmail.com

3. Peter Xavier D'Abreo

: peter dabreo80@hotmail.com

CIBT-JBS is published by the Institute of Business \& Technology - IBT

Main Ibrahim Hydri Road, Korangi Creek, Karachi-75190, Pakistan. 


\section{INTRODUCTION}

\subsection{Overview:}

Markowitz (1952) put forward the groundwork that later on would be known as modern portfolio theory. He participated and experimented on portfolio returns, by finding out that empirically there exists a relationship between the individual securities in the portfolio itself. However the risks that exists in a portfolio have nothing or very little to do with just the risks of the securities itself but also it is the summation of all risks incorporated and opportunity costs, weight ages of the securities, the variance and covariance of the returns connotation as the Markowitz framework or accordingly the variance and mean framework. Later on Tobin (1958) worked on optimality of utility functions of investors and assets return based on mean variance conceptual framework. Lee,1977; Fama,1970; Elton and Gruber,1974 explored alternative portfolio theories with the support of moments and skewness. Mossin,1968; Hakansson,1970; Hakansson,1974; Merton, 1969 observed investors problem in multiperiod and addressed this issue under various assumptions.

The framework of Markowitz was considered too cumbersome in handling voluminous data as it had redundant string of data of the covariance. To bypass this superfluous event Sharp and Linter (1964) discovered a single factor that was logically engaging to the financial community coming up with the "Capital Asset Pricing Model" or (CAPM). This model has been significant for the better part of half a century since its discovery, most prolifically taught model pertaining to finance but critically observed by various researchers due to coverage of single factor and different assumptions like (Baumol, 1963; Leshno \& Levy, 2002; Ross, 1976; Estrada,2007).The investors of the portfolio would require a rate of return based on the return of the securities in the portfolio and the riskiness of the portfolio, which is encompassed in the form of the beta of the portfolio, the higher the security beta, the higher would be the rate of return for the investor due to risk factor.

Notwithstanding the simplicity and the underlying logic the CAPM has upheld results under careful scrutiny. Research has shown that CAPM understates risks by marginalizing the rates of return and risks (Leshno \& Levy, 2002; Ross, 1976; Estrada,2007; Fama \& French,1997). The model also marginalizes two other categories that intuitively do not recognize factors like the size of the firms, and the book to market ratio of the stocks. This raises some serious questions about the validity and reliability of the prediction powers.

The basis of the CAPM relies upon the research undertaken by Markowitz (1959) where the assumptions are that investors are information efficient and are sensitive to risks. Investors would look to factors like mean-variance of the portfolio to measure associated risks. There are two other factors that are combined to the mean-variance of the portfolio. One factor is the risk free rate of return and the second is sensitivity of stock compared to market portfolio.

As all investors are sensitive to the risks associated and the returns generated on the portfolio, and will only take on the investment if the risk premium offsets the security and portfolio risk. The aim of this research is to ascertain the role of Market Risk Premium, Size Risk Premium and Value Risk Premium (based on Fama and French three factor model) on the Excess Return on the selected portfolio developed from selected stock in Pakistan Stock Exchange (formerly Pakistan Stock Exchange). 
First chapter gives introduction of the research area with aims and objectives. Second chapter covers literature review while third chapter provides research methodology. Fourth chapter is conclusion.

\section{LITERATURE REVIEW}

Black (2006) uses the Fama and French Three Factor Model to study the Macroeconomic risks. The study proposes that the Capital Asset Pricing Model (CAPM) does not fully factor in the excess returns on the portfolio above the risk free rate, and therefore a better substitute in the form of the three factor model is developed. This particular study analysis the sensitivity of the returns on the portfolio is the differential of the portfolio returns on small companies as compared to returns on big companies or small minus big (SMB),known as the size premium. It also considers market value, which is the differential of high- book- to-market stocks minus low-book to market stocks, typically know as the value premium for companies. The paper provides empirical evidence that supports the FF(Fama and French Three Factor Model) model of the value risk premium and small companies risk premium.

Drew, Malin, and Veeraraghavan (2006) use FF to elaborate that there exists a high correlation between idiosyncratic volatility between size of the firm and expected rate of return. The questions that they set out to answer were whether an asset-pricing-model using multiple factors can be used efficiently to predict cross-sectional returns. The data collected from Germany and United Kingdom stock exchanges and were divided into six categories based on small vs. large and book vs. market, namely S/L, S/M, S/H, B/L, B/M B/H. The results for this experiment and in particular Germany confirmed the significance of the Fama and French Three Factor Model in that the contribution of small firms is positive while the contribution of big firms is negative to the variable (SMB). Returns of smaller firm with high idiosyncratic volatilities are more risky than larger firms with lower idiosyncratic volatilities. For the United Kingdom results were contrasting than of Germany, where in the UK, it was the big firms with high idiosyncratic firms produced greater returns. The conclusion reinforces the Fama and French Three Factor Model which showed that returns are correlated with idiosyncratic volatilities of the firm.

Trimech, Kortas, Benammou, and Benammou (2009) exploited the wavelet transformation which would subsequently spread into components that would depict mechanism on timescale, and its integration with the Fama and French Three Factor Model. The advantage of this was to portray financial data over singular time horizons. This was compiled using the data from the French stock exchange for a period of twenty years. The outcome of the research proposed that the F\&F Model's predication increased as the wavelet in the studies increased. And that a multiple sectional analysis at the intersections were better in understanding the returns that a single proxy variable. A significant contribution of the research was the risk and returns were highly correlated using the wavelet method along with portfolios constructed on the basis of targeted time (investment horizons) which the Fama and French Model allow.

Zaretzki, and Zumwalt (2007) studied that the firms with the largest distress risk (less profitability and poor market multiples) would also have high $\mathrm{B} / \mathrm{M}$ ratios. A strong negative relationship is established with distress risk and size of the firm. Conversely it is still not fully understood whether the factors establish a systematic risk as a symptom of financial distress or not and whether the markets would need an additional premium to take on this burden. Five zero investment strategies are probed. The fifth strategy used the Fama and French 
based on the three factor theory, as an efficient predictor for asset pricing. Distressed firms (accounting for losses) that are small have been found to have $\mathrm{B} / \mathrm{M}$ ratio. Therefore the association of the intersection of $\mathrm{B} / \mathrm{M}$ and returns has not been proved to be a statistically significant variable in the prediction. The firms in the NYSE, AMEX markets that are distressed, have been found to have a high $\mathrm{B} / \mathrm{M}$ ratio are earning a high return.

Ward, and Djajadikerta (2009) analyzed the BM, Size and momentum impacts of the Fama and French model in New Zealand. The underlying concept was that F\&F model would be a better predictor that the CAPM model since the more factors it possessed. Given that this model was developed in the United States and very few tests were conducted to ascertain the robustness of the model outside and that the conclusions were fully not understood or tested using a wide array of sizes, values and markets. Other issues addressed were seasonality's and factor loading or whether other models like four factors Carhart model was more efficient in forecasting. Six portfolios were formed at the intersection of Small, Medium and Large with factors Market, Size and Value. The three factor theory remained significant for all three factors but however was powerless in explaining the momentum impacts.

Guan, Hansen, Leikam, and Shaw (2007) set out to investigate that the CAPM does not take into account the idiosyncratic variables that help elucidate the cross sectional returns in asset modeling. Also CAPM does not account in the exact shifting in the beta like in the way statistical models gave explanation. And even if CAPM makes the prediction of the expected returns the factors and proxies used may have high correlation with the returns rather than just explaining it. Even though the researchers propounded that Fama and French (1992) was not statistically significant in establishing a association with the beta and cross sectional returns in turn to prove that the Fama and French Model thus directly sets out to nullify the CAPM.

Beaulieu, Gagnon, and Khalaf (2009) set out to ascertain about financial integration in the North American stock markets. Using an improvised Fama and French Model incorporated with momentum factors for each variable. Built on the cross sections of partial, mild and strong, factors are used in the financial integration. Based on the countries of the United States and Canada, the results thereof are that there is greater confirmation of "mild" as compared to "partial" or "strong". However these results can be credited to the explanatory power of the model. Factoring in this shortcoming the researchers concluded that the risk premiums in the model are not statistically significant and that the evidence is similar integration in both United States and Canada's markets.

Verma (2011) showed the forecasting influence of the qualified association of beta and international stock returns. The respective betas of each of the countries are estimated using the method of OLS. The relationship between returns and the beta is tested by using linear regression on cross sectional analysis. Results were not in favor of the model and it was found to be statistically insignificant. This work was furthering the work of the Fama and French Model in which the three factor theory was an alternative and better predictor than the CAPM in which the beta's contribution was significant but however did not account for various systematic risks. The FF Three Factor Model and its importance of the beta in prediction made it a point for researchers to consider its importance and delve into the area of the beta and CAPM. Another limitation was that this model only accounted for the beta and not the whole CAPM which accounts for other extraneous variables which would have a stronger relationship with the returns. The study also sites that some of the other limitations were that the beta's did not account for the lag values as otherwise would be intuitively have an impact on the next periods return. 
Simlai(2009) found how common stock performs with the aid of two popular variables that are used in its measurement, the size and book to market ratios. Researcher used NYSE and AMEX data from 1926 and 2007. The findings of the study were that the two variables proved to have a statistically significant role in encompassing volatility, stock returns, and time series variations. The size and book ratios are based on the data provided by Kenneth French's website and based on six B/M portfolios. The theoretical concepts of the study provides that there is a difference in the risk premium for various assets not only because of the systematic risk but also because of particulars of the security itself like encompassing the size, market to book values etc. And one could expect a higher rate of return (excess premium) based on these factors. The findings of this report were that the F \& F Three Factor Theory proved to be successful in explaining excess return (the dependent variable) by market, size and value (the independent variables).

Kubota and Takehera (2010) proposed a model that expanded on the Fama and French Three Factor Model and proposed a five factor model. This model was projected to better predict systematic risk giving the more accurate predictor given the two respective models. The two additional factors that were taken into consideration were LMW (Losers minus Winners) and the last factor were from Kenneth French's own research UMD (Up minus Down), this factor is based on the liquidity which was IML (Illiquid minus Liquid). In the completion of the research other econometric tests were also employed like the GMM (Generalized Method of Moments) and the Euler Condition Test for multifactor's as well as the Mean-Variance Efficiency Tests. The results showed that the multifactor model was superior in the prediction and forecasting .

Lee, Faff, and Rekker (2012) used the traditional Fama and French Three Factor Model and included momentum as well as industry specific factors. Ranking of the Portfolios were based on the Rating Agency based on the Dow Jones Global Index and their set criterion as well as SAM (Strategic Asset Management) Group. Ten portfolios were used in the regression test and three industry variables were identified using PCA (Principal Component Analysis). The results were that low or high ranked portfolios were superior to the other. Other than the regression the Portfolio was tested for CSP (Corporate Social Performance) which is defined as the returns of high ranking CSP minus the returns of the low ranking CSP. Both leading and lagging factors were employed in this CSP which created four categories based on ranking and whether the factors were leading or lagging. The outcome of the CSP tests was that there is no significant difference between high rankings vs. low ranking CSP's.

Gosnell and Nejadmalayeri(2010) sought out to investigate whether macroeconomic news and announcements had an effect on the Fama and French Three Factor Model. And this study was conducted by taking the daily macroeconomic factor shocks and gauged them on the Model's volatility. Macro factors in this study were mainly inflation, nonfarm payroll and GDP were found to decrease the risk premium, and personal income had the opposite to the size premium in that it increased it. Some macro factors affected one single variable in the study while most affected multiple variables.

Liang (2012) study was based on the momentum and information asymmetry like behavioral finance specifically overreaction and under reaction of investors to private and public information. And their effect on asset prices and display that information can be significant in the momentum of returns and which cannot be elucidated by the Fama French Model.

Study concluded that greater asymmetric information commanded a greater risk premium. Notwithstanding the fact of the matter of private information could also be used to earn 
higher return, the fact that insider trading verged on the illegal side. The informationally efficient traders believed that asset prices did not reflect information within the market, while the informationally deficit traders believed that asset prices reflected information within the market.

Sehgal, and Jain (2014) methodology was concerned with generating portfolios based on specific characteristics and then regressed on factors like Fama and French three and four factor model. Results generated were that the CAPM was substandard at explaining the returns and that the FF three and four factors were highly superior predictors. The portfolio is controlled for momentum as recommended by the Fama \& French Model since momentum can be interpreted in differences in the variables risk and excess return required for justifying these variables. The researches implications follows the contrarian view to investment as well as that emerging markets have a low correlation to that of mature markets, framed in the Indian context.

Pyo and Shin (2013) study was based on the profits that could be generated by using momentum in the Korean Stock Exchange. The systematic risk of the Fama French Model is also checked to ascertain whether affects profits of the momentum portfolios. The study also seeks to determine whether the excess returns of the Fama French Model are based on momentum or contrarian strategies. Momentum return can be computed as the differential between the top deciles return companies to the bottom deciles return companies. The contrarian is simply computed as the return of bottom companies minus the return of the top companies. The SMB variable and the HML variable are divided in three categories making the intersection of six categories in the portfolios. The study confirms the time series association between momentum and returns.

Chen, Chen and Kao (2008) paper was based on the extended term performance of IPO's in the Taiwan Stock Market. This research was based on the newly issued offerings to the public and built-in the Fama and French Three Factor Model as well as two additional factors, namely liquidity and leverage. The paper discussed how survivorship of newly issued IPO's were a major factor contributing to health of the Taiwan Stock Exchange. A multiple regression of the data showed all variables to be significant except for the variable HML. Chen (2002) result also confirmed by it. Since these rates of survivorship were high, hence researchers concluded that the stock market would be healthy in the extended term. The two additional factors mainly liquidity and leverage in addition to the traditional Fama and French Three Factors were observed to be more robust.

Blazenko and $\mathrm{Fu}$ (2012) research was about determining the return of value stocks (low B/M) as opposed to growth stocks (high $\mathrm{B} / \mathrm{M}$ ) ratios. It was conducted to further elucidate the phenomenon that with additional risk of value stocks comes additional returns to the stockholder, while returns already is included in the capital expenditure growth costs to the firm which diminishes the riskiness to growth companies. Researcher concluded that the firms profit improved investors returns in value companies as compared to the growth companies.

Being researcher we viewed after extensive study of literaure review that we should explore basic Fama and French Three Factor Model in the case of Pakistan to explore its predictiblity in case of developing company by taking the Size Risk Premium, Market Risk Premium,and Value Risk Premium that impact the Excess Return of the Portfolio. This will pave the way to further explore Pakistan Stock Exchange by applying various models after certain modifications as discussed in literature. 
Hypotheses to be tested are as follows.

$H_{1}$ : The Market Risk Premium of the companies has a significant impact on Excess Return of the portfolio.

$\mathrm{H}_{2}$ : The Size Risk Premium of the companies has a significant impact on Excess Return of the portfolio.

H3: The Value Risk Premium of the companies has a significant impact on Excess Return of the portfolio.

\section{RESEARCH METHODS}

The data collected from Pakistan Stock Exchange (formerly Pakistan Stock Exchange) listed companies and from State Bank of Pakistan. The sample period chosen and the duration that the firms listed on the exchange are from December 1994 to December 2012 on a semiannual basis.

To achieve the purpose of this research the annual returns of 40 firms listed for a period of 18 years on a semiannual basis on the Pakistan Stock Exchange were considered. Moreover economic indicators are also included for the same period. The selected companies must have existed for the entire duration (December 1994 to December 2012) and actively traded in stock exchange.

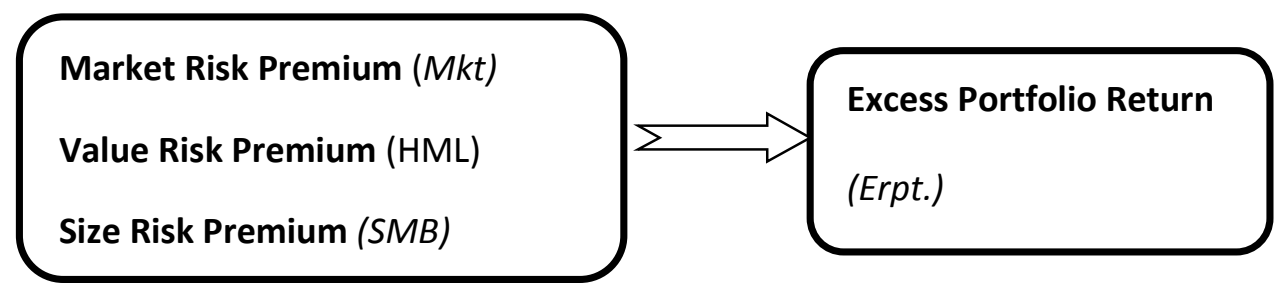

Source: Prepared by author

Panel Least Squares (PLS) was applied to determine the relationship of excess returns and three independent variables (Market, Size and Value Premiums).

Excess Return on Portfolio $=\alpha_{0}+\beta_{1} \mathrm{SMB}+\beta_{2} \mathrm{HML}+\beta_{3} \mathrm{MKT}+€$

\section{Findings and Interpretations of the results}

In this section we summarize our statistical result based on data from Pakistan Stock Exchange. Table 3.1 is the regression result based on the Panel Least Squares (PLS) method. We devote our attention to overall long term model established based on Fama and French three factor model. Total number of observations used for the entire portfolio is 1425

The F statistics in table 3.1 is significant and prediction is possible. It shows that the model is best fit in case of developing economy and can be used with existing independent variables. The adjusted R-square shows that independent variables explain around 20\% variation in dependent variable i.e. excess return obtained from stock after adjusting for risk free rate of Pakistan while (Fama \& French, 1996) model explained around 0.93. It may be due to application of model on developed economy of USA. Model is free of Heteroscedasticity and Multicollinearity. It seems that three factor model in Pakistani scenario capture greater part of cross sectional deviation in stock return. Bondt and Thaler (1985) formed portfolio based on long term (three to five years) and showed that companies 
that had low past returns provided high future returns and vice versa. La Porta (1996) supported the view. We could not support this finding based on our result.

Table 3.1 shows that all independent variables are significant and have sign as predicted by theoretical understanding. From our result we interpret that three factors model explain returns in its simplified form on long term horizon. Future research is open on short term horizon.

The variable HML (independent variable) shows a positive impact on the (dependent variable) Excess Return with the coefficient of $15.12 \%$ increase for every $1 \%$ increase in the independent variable. The variable MKT (independent variable) shows a positive impact on the (dependent variable) with a coefficient of $65.65 \%$ for every $1 \%$ increase in the independent variable. The variable SMB (independent variable) has a negative impact on the (dependent variable) with a coefficient of $12.72 \%$.

We concluded that as observed by (Fama \& French, 1996) that only covariance of stock with the market return is not enough to measure risk and return, hence multifactor model is better predictor to measure returns. It is a good model which not only covering sensitivity of market portfolio but also taking into consideration size and book to market variables. Two variables (MRP) and (HML) have a positive impact on the dependent variable (ERPT), while one variable (SMB) have a negative impact on the dependent variable.

\section{CONCLUSION}

This research was based to test the application of Fama of French three factor models on emerging stock market. Excess Return calculated on Portfolio of selected stocks from Pakistan Stock Exchange and three independent variables (Market Risk Premium (MKT), Size Risk Premium (SMB) and Value Risk Premium (HML) were taken for a period of 18 years on a semiannual basis and well as other macro indicators. Result is significant which highlights the fact that three factor model can be used in emerging market like Pakistan. The outcome of the statistical test shows that out of the three predictors all are significant. Two out of the three variables namely MKT and HML have a positive sign while one variable SMB has negative sign.

Market Risk Premium (MRP) positive sign justify the risk of investing in the portfolio with higher excess return. This is consistent with the findings and supporting results of positive impacts by ( Kim,1997; Banz,1981; Verma, 2011; Ward and Djajadikerta 2009).The variable of Value Risk Premium (HML) coefficient's positive impact of $15 \%$ increase in excess return. This means that Value stocks are outperforming growth stocks in Pakistan Stock Exchange. These findings are consistent with the results of positive impacts were also found by Blazenko and Fu (2012) and also in Black (2006).The variable of Size Risk Premium (SMB) showed negative. This means that big companies of Pakistan Stock Exchange demand a greater excess return on their stock as compared to smaller companies listed on Pakistan Stock Exchange. Result is consistent with earlier findings by (Gagnon \& Khalaf ,2009; Ward \& Djajadikerta 2009).

The evidence presented in this paper suggested that rather than using CAPM with one variable, developing economy market investors and portfolio managers can also rely on three factor model to predict excess return. Though lack of comprehensive data may cause problem to apply variety of other variations in variables, testing and application of various models. Recommendation for future research in this area suggests that factors like systematic co skeweness and systematic co kurtosis should be taken into account to enhance the 
prediction of the fresh model. Kubota and Takehera (2010) proposed a model that expanded on the Fama and French Three Factor Model and proposed a five factor model.

\section{REFERENCES}

Banz, R. W. (1981). The relationship between return and market value of common stocks. Journal of financial economics, 9(1), 3-18.

Baumol, W. J. (1963). An expected gain-confidence limit criterion for portfolio selection. Management science, 10(1), 174-182.

Beaulieu, M.-C., Marie Helene, G., \& Khalaf, L. (2009). A cross-section analysis of financial market integration in North America using a four factor model. International Journal of Managerial Finance , 5 (2), 248-267.

Black, A. J. (2006). Macroeconomic risk and the Fama-French three-factor model. Journal of Managerial Finance, 32 (6), 505-517.

Blazenko, G. W., \& Fu, Y. (2012). Value versus growth in dynamic equity investiong. Journal of Managerial Finance, 39 (3), 272-305.

Bondt, W. F., \& Thaler, R. (1985). Does the stock market overreact?. The Journal of finance, 40(3), 793-805.

Chen, A., Chen, L.-W., \& Kao, L. (2010). Leverage, liquidity and IPO long-run performance: evidence from Taiwan IPO markets. International Journal of Accounting and Information Management, 18 (1), 31-38.

Drew, M. E., Malin, M., Naughton, T., \& Veeraraghavan, M. (2006). Idiosyncratic volatility and security returns: evidence from Germany and United Kingdom. Studies in Economics and Finance , 23 (2), 80-93.

Fama, E. F. (1970). Multiperiod consumption-investment decisions. The American Economic Review, 60(1), 163-174.

Fama, E. F., \& French, K. R. (1997). Industry costs of equity. Journal of financial economics, 43(2), 153-193.

Fama, E. F., \& French, K. R. (1996). Multifactor explanations of asset pricing anomalies. The journal of finance, 51(1), 55-84.

Elton, E. J., \& Gruber, M. J. (1974). Portfolio theory when investment relatives are lognormally distributed. The Journal of Finance, 29(4), 1265-1273.

Estrada, J. (2007). Mean-semivariance behavior: Downside risk and capital asset pricing. International Review of Economics \& Finance, 16(2), 169-185.

Gosnell, T., \& Nejadmalayeri, A. (2010). Macroeconomic news and risk factor innovations. Journal of Managerial Finance, 36 (7), 566-582.

Guan, L., Hansen, D. R., Leikam, S. L., \& Shaw, J. Stable betas, size, earnings-to-price,bookto-market and the validity of the capital asset validity of the capital asset pricing model. Journal of Managerial Finance, 33 (8), 595-614.

Hakansson, N. H. (1970). Optimal investment and consumption strategies under risk for a class of utility functions. Econometrica: Journal of the Econometric Society, 587-607.

Hakansson, N. H. (1974). Convergence to isoelastic utility and policy in multiperiod portfolio choice. Journal of Financial Economics, 1(3), 201-224.

Kim, D. (1997). A reexamination of firm size, book-to-market, and earnings price in the cross-section of expected stock returns. Journal of Financial and Quantitative Analysis, 32(04), 463-489.

Kubota, K., \& Takehara, H. (2010). Expected return, liquidity risk, and contrarian strategy: evidence from the Tokyo Stock Exchange. Journal of Managerial Finance , 36 (8), 655-679. 
La Porta, R. (1996). Expectations and the cross-section of stock returns.The Journal of Finance, 51(5), 1715-1742.

Lee, D. D., Faff, R. W., \& Rekker, S. A. (2013). Do high and low-ranked sustainability stocks perform differently? International Journal of Accounting and Information Management , 21 (2), 116-132.

Lee, C. F. (1977). Functional form, skewness effect, and the risk-return relationship. Journal of financial and quantitative analysis, 12(01), 55-72.

Leshno, M., \& Levy, H. (2002). Preferred by "all" and preferred by "most" decision makers: Almost stochastic dominance. Management Science,48(8), 1074-1085.

Merton, R. C. (1969). Lifetime portfolio selection under uncertainty: The continuous-time case. The review of Economics and Statistics, 247-257.

Mossin, J. (1968). Optimal multiperiod portfolio policies. The Journal of Business, 41(2), 215-229.

Nartea, G. V., Ward, B. D., \& Djajadikerta, H. G. (2009). Size, BM, and momentum effects and the robustness of the Fama-French three-factor model Evidence from New Zealand. International Journal of Managerial Finance , 5 (2), 179-200.

Pyo, U. H., \& Shin, Y. J. Momentum profits and idiosyncratic volatility: the Korean evidence. Review of Accounting and Finance, 12 (2), 180-200.

Ross, S. A. (1976). The arbitrage theory of capital asset pricing. Journal of economic theory, 13(3), 341-360.

Sehgal, S., \& Jain, S. Long-term prior return patterns in stock and sector returns in India. Journal of Advances in Management Research, 11 (2), 192-210.

Simlai, P. (2009). Stock returns, size, and book-to-market equity. Studies in Economics and Finance, 26 (3), 198-212.

Tobin, J. (1958). Liquidity preference as behavior towards risk. The review of economic studies, 25(2), 65-86.

Trimech, A., Kortas, H., Benammou, S., \& Benammou, S. (2009). Multiscale Fama-French model: application to the French market. The Journal of Risk Finance , 10 (2), 179192.

Verma, R. (2011). Testing forecasting power of the conditional relationship between beta and return. The Journal of Risk Finance, 12 (1), 69-77.

Zaretzky, K., \& Zumwalt, J. K. (2007). Relation between distress risk, Relation between distress risk, premium. Journal of Managerial Finance , 33 (10), 788-797. 


\section{APPENDIX 1}

Table 3.1

\begin{tabular}{lllll}
\hline \hline Variable & Coefficient & Std. Error & t-Statistic & Prob. \\
\hline \hline HML & 0.151279 & 0.048129 & 3.143190 & 0.0017 \\
MKT & 0.656528 & 0.044432 & 14.77611 & 0.0000 \\
SMB & -0.127234 & 0.058264 & -2.183749 & 0.0291 \\
C & 1.625358 & 1.004342 & 1.618331 & 0.1058 \\
\hline \hline & $=$ & & \\
R-squared & 0.197770 & Mean dependent var & -0.620723 \\
Adjusted R-squared & 0.196076 & S.D. dependent var & 41.23382 \\
S.E. of regression & 36.97098 & Akaike info criterion & 10.06095 \\
Sum squared resid & 1942299. & Schwarz criterion & 10.07572 \\
Log likelihood & -7164.425 & Hannan-Quinn criter. & 10.06646 \\
F-statistic & 116.7709 & Durbin-Watson stat & 1.905538 \\
Prob(F-statistic) & 0.000000 & & \\
\hline \hline
\end{tabular}

